\title{
PERSPECTIVES ON SUSTAINABLE DEVELOPMENT IN THE CONTEXT OF PUBLIC HEALTH ISSUES
}

\author{
Ioana-Codruta, RACZ \\ PhD Fellow, SOP HRD/159/1.5/S/133675 Project, "Lucian Blaga” University of Sibiu, Partner, Romania
}

\begin{abstract}
Health is an integral part of sustainable development, a process that can't be materialized if there is a high prevalence of diseases, a high percentage of those is due to environmental factors. An important component of health is the healthy nutrition, especially of children and pregnant women. Iodine is an essential micronutrient for a good nutrition that covers the physiological needs of the body, iodine deficiency having important consequences for mother and fetus, then for children, especially in the first years of life. The main role of iodine in the body is due to his importance for synthesis of thyroid hormones involved in growth and development of psychic and somatic body, starting with intrauterine life. Iodine deficiency was, and still is, a public health problem, globally the most affected countries are in Central Africa, central South America and northern Asia. Europe iodine deficiency is relatively lower. Multiple interventions were made to improve and even eradicate iodine deficiency disorders, in particular through the universal iodization of salt for human consumption, but must be supported in continuing efforts because this issue is not fully resolved to this day.
\end{abstract}

KEY WORDS: children, iodine deficiency, health

\section{INTRODUCTION}

Sustainable development is a concept that has crystallized over time, over the years, and it can be simply defined as a better quality of life for the entire population, both now and for future generations. The sustainability of the society marks the balance between economic and social development in relation to the efficient use and conservation of the environment.

The issue of the relationship between man and the environment became the concern of the international community since the United Nations Conference on the Human Environment (Stockholm, 1972) and resulted in the work of the World Commission on Environment and Development, established in 1985. The report of the Commission presented in 1987 by GH Brundtland and entitled "Our Common Future" offered first accepted definition of sustainable development as "development that meets the needs of the present generation without compromising the ability of future generations to meet their own needs". ${ }^{1}$ From here, sustainable development issues were intensely debated at the World Conference on Environment and Sustainable Development in Rio de Janeiro in 1992, and the World Conference on Sustainable Development in Johannesburg in 2002.

Based on the principles of sustainability, some of the most important goals of sustainable development are the environmental protection, which allow a socio-economic development of the entire population, maintaining health and also combating global public health issues that affect a substantial percentage of Earth's population.

\section{IODINE DEFICIENCY - MAJOR PUBLIC HEALTH PROBLEM}

An important determinant of health status of a population is represented by a healthy diet, proper for the physiological needs, particularly for mother and child.

Growth status is considered the best indicator of child wellbeing, conditioned by socio-economic and health status of a population. Among nutritional factors, an important role in child health, even intrauterine life, have iron and iodine, which justifies the importance given their status in pregnant women and in children. ${ }^{2}$

In the next paragraphs, we will mainly discuss the role of iodine in the body, the effects of iodine deficiency especially in children and pregnant women with important repercussions on the fetus, iodine deficiency being one of the major public health problems affecting people worldwide.

Iodine is an essential element in the body ensuring growth, well development and functioning of all organs and systems. Its action is achieved by the fact that it has an important role in the formation of thyroid hormones, substances regulating metabolic processes of all human body organs. ${ }^{2}$ Thyroid hormones are essential to the growth and maturation of cartilage chondrocytes, awareness to action of GH (growth hormone). Deficiency of thyroid hormones from birth is known as congenital myxedema. In children, in addition to their classical roles of metabolic regulation, and cardiovascular, thyroid hormones have three essential functions: maturation of the central nervous system, maturation of the cartilage growth by raising them to the action of growth hormone and maturation of the surfactant to provide a good mechanic 
ventilation. ${ }^{3}$ Thus, since intrauterine life, thyroid hormones influence brain development of the fetus, pregnant women in this context requires additional intake of iodine, which provide all these functions.

Unlike other nutrients, iodine does not occur naturally in food, the highest content of iodine is in sea fish or seafood, but these products are not available to a wide range of the population. ${ }^{2}$ Iodine is present in the soil and iodine deficiency is a result of its uneven distribution in the ground, mountain and foothill areas with a low iodine content, as a result of past ice ages, when heavy rains and floods have "washed" iodine from soil to the seas and oceans. Food grown on soils deficient in iodine also can't satisfied the physiological needs of the population living in those areas.

Iodine deficiency disorders, which may begin before birth, are threatening children's mental health and often even their survival. Iodine deficiency during pregnancy may lead to stillbirth, miscarriage or congenital abnormalities such as cretinism. ${ }^{4}$ Cretinism is characterized by short stature and mental retardation and occurs when children in iodine deficient areas do not receive in the first years of life iodine or hormone replacement therapy so as to reach the normal thyroid hormones. These children are often born to mothers with iodine deficiency and perhaps maternal thyroid hormone deficiency which cause worsening of the disease. ${ }^{5}$

Iodine deficiency is found in many mountainous regions in central Africa, central South America and northern Asia. In Europe iodine deficiency remains slightly decreased, and studies have shown that iodine intake has been declining in the United States and Australia. ${ }^{5}$ In Romania, low iodine intake occurs in mountain and foothill areas, around the Carpathian Mountains or Plateau Transylvania, Sibiu County being one of those regions.

\section{EVOLUTION OF IODINE STATUS OF THE POPULATION}

After more than 20 years, few people realized the magnitude of the problem of iodine deficiency, not to mention a solution. Since the 1980s, the World Health Organization has been at the forefront of public health units worldwide to eliminate this deficit under-publicized, but so devastating. The organization provides both technical tools and technical guidance to build national programs of salt iodization. ${ }^{4}$ This programs of salt iodization for human consumption have been established in collaboration with UNICEF, ICCIDD (International Council for Control of Iodine Deficiency Disorders), international agencies and national and salt industry.

Progress has been dramatically from primary strategy for the control of iodine deficiency disorders - universal salt iodization - which was adopted in $1993 .^{4}$

In Romania, the "National Strategy for Elimination of Iodine Deficiency Disorders through Universal Salt Iodization for direct human consumption and production of bread during 2004-2012" was developed and proposed to the Government of Romania by the Ministry of Health - General Directorate of Public Health and Sanitary Inspection. ${ }^{6}$ Worldwide statistics show that: 1.6 billion people are at risk of being affected by dietary iodine deficiency, iodine deficiency disorders affect 50 million children, and each year are born 100,000 children worldwide with cretinism. ${ }^{6}$

WHO studies have shown that global iodine status improved after the introduction of iodized salt for human consumption, data was collected from 2003 to 2007. More and more countries collect information and monitor this progress, so there is an increase in the global database regarding iodine deficiency. In fewer countries iodine deficiency was considered a public health problem in 2007 than it was considered in 2003. ${ }^{7}$ Although the results are getting better and more visible, iodine deficiency remains a public health problem in several countries, requiring surveillance especially of pregnant women, because they are a special group most susceptible to the effects of iodine deficiency, effects that are seen later in children.

More recent studies have been conducted on iodine deficiency showing that in 2013, approximately $70 \%$ of households worldwide have adequate access to iodized salt, compared to about only $10 \%$ in 1990, when the United Nations World Summit Children set the goal of eliminating iodine deficiency globally. ${ }^{8}$ The progress in the fight against lack of iodine has declined in recent years, for various reasons, technical or political, so that the problem lies increasingly discussed today.

Statistics showed in 2013 that: 111 countries have sufficient iodine intake defined as the average urinary iodine concentrations of 100-299 pg/l in school children and $150 \mathrm{pg} / \mathrm{l}$ in pregnant women; 30 countries are considered deficient in iodine deficient of which 21 are slightly deficient and 9 are considered moderately deficient. ${ }^{8}$

In Europe, several recent studies carried out in economically advanced countries (Italy, United Kingdom, Austria), in pregnant women, have shown the persistence of iodine deficiency in the present day. An Italian study enrolled 322 pregnant women, 217 of Italian origin, 62 East European and 43 North and Central Africa, determining urinary iodine to these women. The conclusion was that the iodine level was too low for women in the Italian region studied, and especially in women of foreign nationality, such as iodine supplementation is required during pregnancy. ${ }^{9}$ Another study done in 1040 mothers and their children in the UK, showed that even a slightly lower level of iodine deficiency during pregnancy is associated with adverse effects on child cognitive development. ${ }^{10}$ Another recent study in Austria, made on 246 pregnant women showed that those women in the region of Vienna, have a significant iodine deficiency, and that current recommended dose supplementation with iodine are not suficient. ${ }^{11}$

\section{CONCLUSIONS}

Protecting the health of present and future society in the context of sustainable development, social development and economic development, should take into account first all of these public health problems affecting a significant percentage of the population of the Earth, so as to seek effective ways to combat them. The first step in the fight against iodine deficiency, an important public health problem, was done successfully in recent decades, but it remains a trigger of some diseases that primarily affect pregnant women and children, that for, all the efforts to combat them should be further supported.

In the future, we wish to make known to the public worldwide, not only the need to continue supporting the fight against iodine deficiency, but also the development of algorithms for diagnosis and treatment of iodine deficiency, development of brochures distributed to family doctors in areas deficient in iodine, and not least a prompt and careful evaluation of children with short stature, to intervene with appropriate treatment, be it for another reason, besides iodine deficiency. 


\section{ACKNOWLEDGEMENT}

This paper is supported by the Sectoral Operational Programme Human Resources Development (SOP HRD), financed from the European Social Fund and by the Romanian Government under the contract number POSDRU/159/1.5/S/133675.

\section{REFERENCES}

1. Guvernul Romaniei., Ministerul mediului si Dezvoltarii Durabile., Programul Natiunilor Unite pentru Dezvoltare., Centrul National pentru Dezvoltare Durabila., Strategia Nationala pentru Dezvoltare Durabila a Romaniei Orizonturi 2013-2020-2030., Bucuresti, Romania, (2008).

2. UNICEF, Principii in alimentatia copilului și a gravidei, MarLink ed., Bucuresti, Romania, (2007).

3. Branisteanu, D.D., Tulburarile de crestere. Ghid de diagnostic si tratament, Polirom ed., Iasi, Romania, (2011).
4. WHO, Micronutrient deficiencies. Iodine deficiency disorders.

5. Jameson, J.L., Harrison Endocrinologie, All ed., Bucuresti, Romania, (2014).

6. UNICEF, Reprezentanta in Romania, Strategia Nationala pentru eliminarea tulburarilor prin deficit de iod, Romania 2004-2012, Bucuresti, Romania, (2005).

7. de Benoist, B., McLean, E., Andersson, M., Rogers, M., Iodine deficiency in 2007: global progress since 2003, Food and Nutrition Bulletin, No. 29, pp. 195-202, (2008).

8. Neville, A.N., Iodine Deficiency Still a Concern, Despite vast Improvements, Thyroid, No. 23, pp. 523-528, (2013).

9. Mian, C., et al., Iodine Status in Pregnancy: Role of Dietary Habit and Geographycal Origin, Clinical Endocrinology, Vol. 5, No. 70, pp. 776-780, (2009).

10. Neville, A.N., Iodine Key for IQ. Pregnancy Deficiency Affects Kids Brain, Lancet, (2013).

11. Lindorfer, N., et al., Iodine Deficiency in pregnant women in Austria, European Journal of Clinical Nutrition, (2014). 